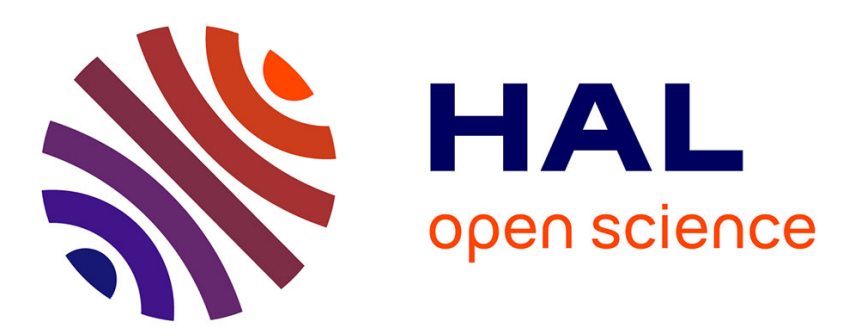

\title{
Dynamical Behaviour of a Plasma Discharge in the Current Regime Limited by the Cathode Temperature
}

\author{
C. Arnas Capeau, G. Bachet, F. Doveil
}

\section{To cite this version:}

C. Arnas Capeau, G. Bachet, F. Doveil. Dynamical Behaviour of a Plasma Discharge in the Current Regime Limited by the Cathode Temperature. Journal de Physique IV Proceedings, 1995, 05 (C6), pp.C6-71-C6-74. 10.1051/jp4:1995613 . jpa-00253976

\section{HAL Id: jpa-00253976 https://hal.science/jpa-00253976}

Submitted on 1 Jan 1995

HAL is a multi-disciplinary open access archive for the deposit and dissemination of scientific research documents, whether they are published or not. The documents may come from teaching and research institutions in France or abroad, or from public or private research centers.
L'archive ouverte pluridisciplinaire HAL, est destinée au dépôt et à la diffusion de documents scientifiques de niveau recherche, publiés ou non, émanant des établissements d'enseignement et de recherche français ou étrangers, des laboratoires publics ou privés. 


\title{
Dynamical Behaviour of a Plasma Discharge in the Current Regime Limited by the Cathode Temperature
}

\author{
C. $\operatorname{Arnas}_{\text {Capeau }}(1)$, G. Bachet(1) and F. Doveil(1) \\ Institut Méditerranéen de Technologie, Technopôle de Château-Gombert, 13451 Marseille \\ cedex 20, France
}

\begin{abstract}
Experimental observations of plasma self-oscillations are presented. In the current regime limited by the cathode temperature of a continuous multipolar discharge, they appear for low gas pressure (collisionless plasma), low cathode heating current and above a discharge voltage threshold. Their frequency and amplitude are strongly dependent on the discharge parameters. The scaling laws of their variation and an example of a perioddoubling route to chaos are reported.
\end{abstract}

\section{INTRODUCTION}

Under particular conditions, plasmas discharge can display chaotic behaviour. The main routes to chaos have been experimentally identified: the period doubling route sequence [1,2], the intermittent [1] and the quasiperiodic routes [3]. The present paper gives a contribution to this subject with a description of the conditions producing low frequency self-oscillations of a continuous discharge. The experiments were performed in a magnetic multipolar device with hot filaments cathodes used to produce a collisionless plasma. In this kind of discharge, the current-voltage characteristic I(U) displays a typical hysteresis curve [4,5] indicating a bistable behaviour. The lower branch of I(U) represents the "space charge current regime', governed by Langmuir's law. The upper branch of $\mathrm{I}(\mathrm{U})$ corresponds to the "'temperature limited current regime" governed by Dushman-Richardson's law.

We report here, new results about self excited oscillations occurring in the I(U) hysteresis upper branch. We observe them in discharge current, saturation probe currents and floating potential, in the absence of any pulsating external force. They appear above a discharge voltage threshold $V_{d s}$. Their amplitude and their frequency depend strongly on the argon pressure $P_{a r}$, the filament heating current $I_{f}$ and the discharge voltage $V_{d}$. We have established the scaling laws of their variations according to these parameters. They qualitatively agree with the cathode instability arising when the Bohm sheath stability criterion is not fulfilled.

\section{EXPERIMENTAL SET-UP AND RESULTS}

The plasma device consists of a stainless steel cylinder $(45 \mathrm{~cm}$ diameter and $80 \mathrm{~cm}$ length). Along the chamber axis, 14 rows of permanent magnets with alternate biasing, completed by 4 rows on each cylinder end door, are arranged to provide primary

${ }^{(1)}$ Equipe Turbulence Plasma de I'URA 773 du CNRS, Univ. de Provence. 
electron confinement. The plasma is produced by a dc discharge between the grounded chamber wall and 4 spiral tungsten filaments $(27 \mathrm{~cm}$ long, $0.03 \mathrm{~cm}$ diameter). The filaments are heated by a current $I_{f}$ delivered by a current regulated power supply. The primary electrons emitted from these hot filaments are accelerated by a negative voltage $\left|V_{d}\right|$ provided by a voltage regulated power supply. The discharge current $I_{d}$ is detected as a voltage drop across a resistor in series with the discharge.

Figure 1 shows an example of the observed self-oscillations which behave like low frequency $(F=220 \mathrm{~Hz})$ relaxation oscillations: a) of the electron saturation probe current $\Delta \mathrm{I}_{e p}$, and $\mathrm{b}$ ) of the discharge current $\Delta \mathrm{I}_{d}$ superimposed to the $\mathrm{dc}$ level $\mathrm{I}_{\mathrm{ep}}$ and $I_{d}$ respectively. The continuous discharge parameters are: $P_{a r}=810^{-5}$ Torr, $I_{f}=27 \mathrm{~A}$ and $\left|\mathrm{V}_{\mathrm{d}}\right|=60 \mathrm{~V}\left(\left|\mathrm{~V}_{\mathrm{ds}}\right|=54 \mathrm{~V}\right)$, providing the average electron (ion) density $\mathrm{N}_{\mathrm{e}}=$ $N_{i}=510^{8} \mathrm{~cm}^{-3}$, the average electron temperature $T_{e}=3.5 \mathrm{eV}$ and the ion temperature $\mathrm{T}_{\mathrm{i}}<<\mathrm{T}_{\mathrm{e}}$.

$\Delta \mathrm{I}_{\mathrm{ep}}$ is measured with a Langmuir probe located in the plasma center and positively biased at $V_{b}=20 \mathrm{~V}$, higher than the plasma potential. In this situation: $\Delta \mathrm{I}_{\mathrm{ep}} / \mathrm{I}_{\mathrm{ep}}=$ 0.065 . The Langmuir current for electrons and the Bohm criterion for ions allow us to write: $\Delta \mathrm{I}_{\mathrm{ep}} / \mathrm{I}_{\mathrm{ep}}=\Delta \mathrm{N}_{\mathrm{e}} / \mathrm{N}_{\mathrm{e}}+1 / 2\left(\Delta \mathrm{T}_{\mathrm{e}} / \mathrm{T}_{\mathrm{e}}\right)$. So, the measured ratio $\Delta \mathrm{I}_{\mathrm{ep}} / \mathrm{I}_{\mathrm{ep}}=0.065$ gives a global information about the relative variation of the electron density and temperature during one self-oscillation period of the ionization process. $\Delta I_{d}$ is measured at the same time [Figure $1(b)] . I_{d}$ is proportional to $N_{e p}$, the primary electrons density injected into the discharge volume. As a consequence, when $\mathrm{N}_{\text {ep }}$ increases (respectively decreases) the ionization probability and then the plasma density, also increases (respectively decreases). So, both signals in Figure 1 (a) and 1 (b) have the same shape and are in phase.

a)

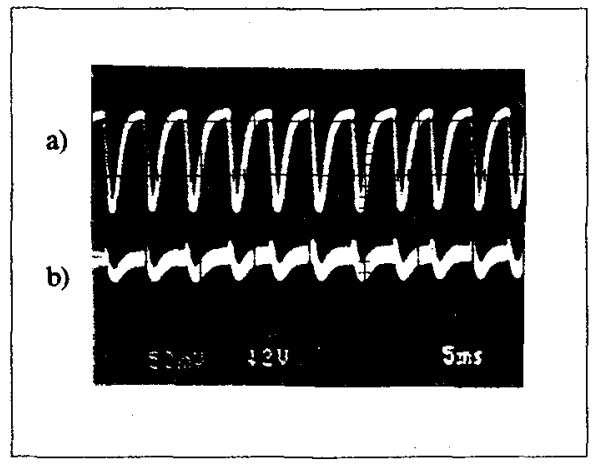

Figure 1

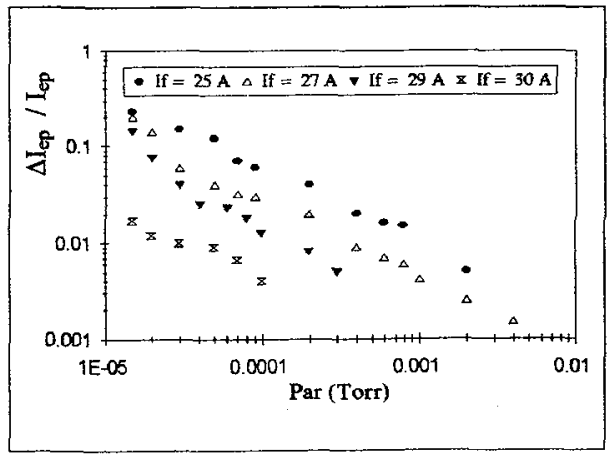

Figure 2

Figure 1: Self-oscillations amplitude: a) of the electron saturation probe current $\Delta I_{e p}$, b) of the discharge current $I_{d}$

Figure 2: Amplitude variation of $\Delta \mathrm{I}_{\mathrm{ep}}$ normalized to the corresponding de current $\mathrm{I}_{\mathrm{ep}}$ versus Par, for different $I_{f}$.

The self-oscillations are sensitive to the discharge parameters. Their amplitude and frequency depend on $P_{a r}, I_{f}$ and $V_{d}$. Figure 2 gives the variation of $\Delta I_{e p} / I_{e p}$ versus $P_{a r}$ (1.5 $10^{-5}$ Torr $\leq P_{\text {ar }} \leq 910^{-3}$ Torr), for different $I_{f}$. For a given $I_{f}$, when $P_{a r}$ is 
increased, the ratio $\Delta \mathrm{I}_{\mathrm{ep}} / \mathrm{I}_{\mathrm{ep}}$ decreases while, at the same time, the mean selfoscillation frequency increases. So; the oscillations turn into noise when the neutral

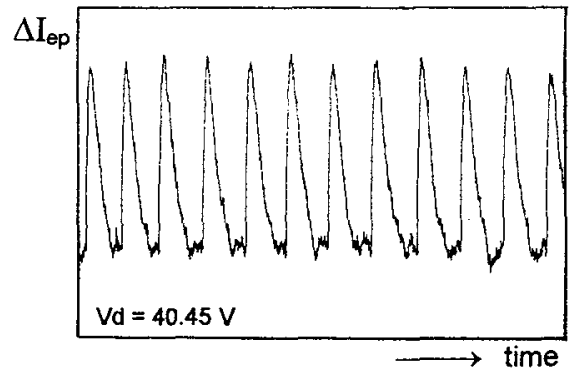

a)

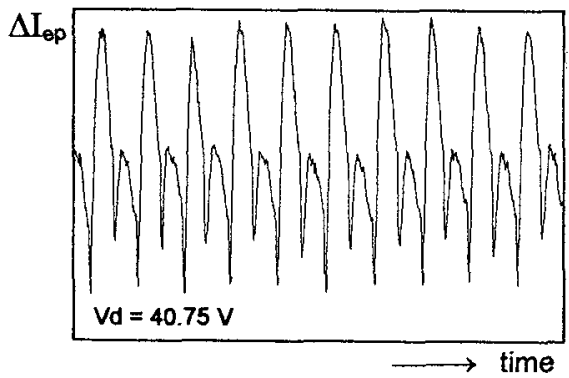

b)

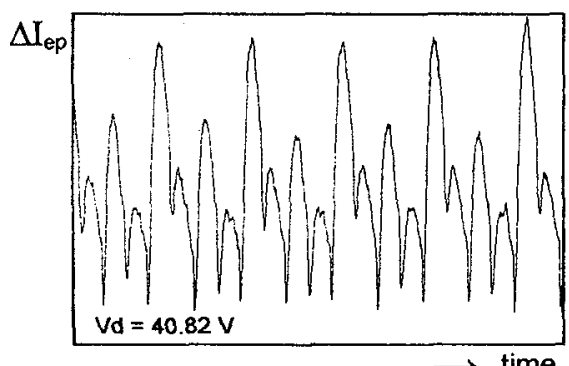

c)

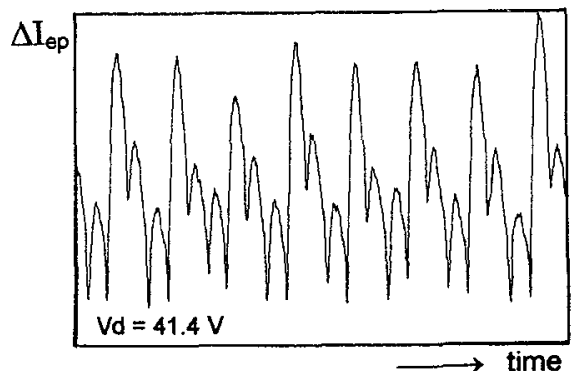

d)

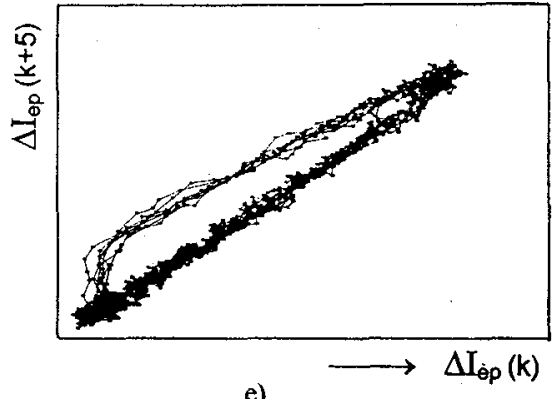

e)
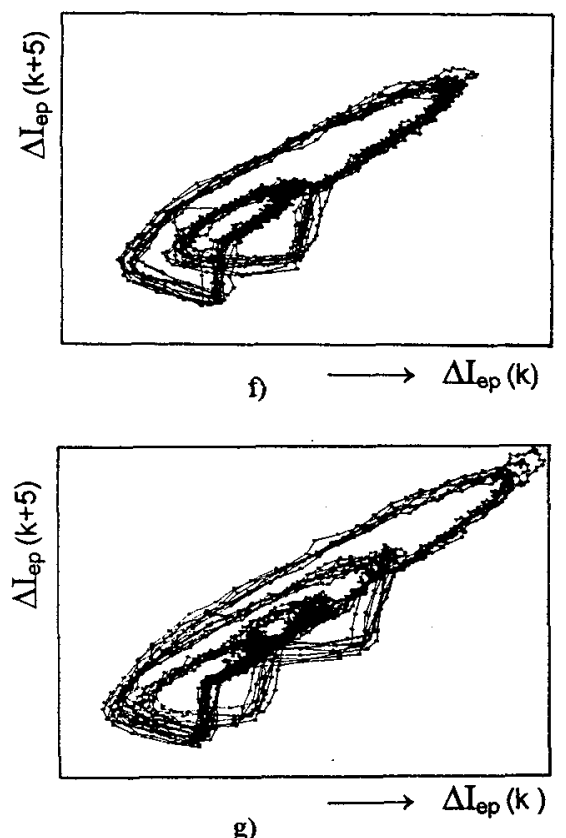

g)

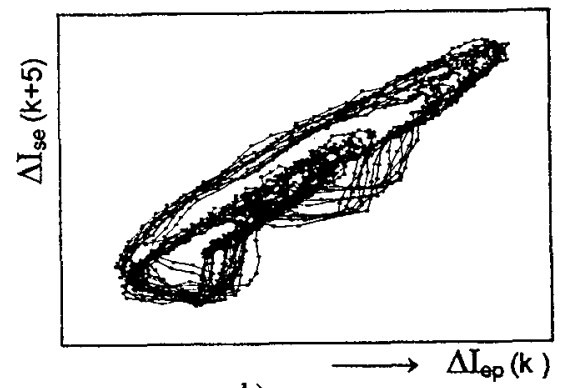

h)

Figure 3: Period doubling route to chaos. The left traces show the oscillations $\Delta \mathrm{I}_{\mathrm{ep}}$ obtained for: a) $V_{d}=40.45 \mathrm{~V}$, b) $V_{d}=40.75 \mathrm{~V}$, c) $V_{d}=40.82 \mathrm{~V}$, d) $V_{d}=41.4 \mathrm{~V}$. The rigth traces are the corresponding trajectories obtained by plotting the data at time step $(k+5)$ versus the data at time step $k$. 
gas pressure rises or when the plasma density is increased. The same observation can be done for a given $P_{a r}$ : when $I_{f}$ increases, the mean self-oscillations frequency increases and $\Delta I_{e p} / I_{e p}$ decreases. So, when $N_{e p}$ is important (the plasma density $N_{e}$ is important), the ionization oscillations disappear.

In Figure 3, we present an example of the frequency change with $V_{d}$. The left-most traces show $\Delta \mathrm{I}_{\mathrm{ep}}$ oscillations sampled by a 12 bit $\mathrm{DA}$ converter. The graphs on the right side are the corresponding trajectories. They are obtained by plotting the amplitude $\Delta \mathrm{I}_{\mathrm{ep}(\mathrm{k}+5)}$ of the $(\mathrm{k}+5)^{\text {th }}$ time step sample versus the amplitude $\Delta \mathrm{I}_{\mathrm{ep}(\mathrm{k})}$ of the $\mathrm{k}^{\text {th }}$ time step sample. By rising the control parameter $\left|\mathrm{V}_{d}\right|$, we observe a period doubling route to chaos. Oscillations follow the sequence $\mathrm{T} \rightarrow 2 \mathrm{~T} \rightarrow 4 \mathrm{~T} \rightarrow$ chaos, where $2 \mathrm{~T}$ and $4 \mathrm{~T}$ mean the state of period 2 and 4 respectively and $\mathrm{T}=11 \mathrm{~ms}$.

\section{DISCUSSION}

A possible explanation for the onset of the self-oscillations arises from the Bohm sheath stability criterion given by: $\frac{j_{\text {ep }}}{j_{i}} \leq \sqrt{\frac{m_{i}}{m_{e}}}=270$ for argon, where $j_{\text {ep }}$ and $j_{i}$ are the primary and ion current densities. The particle balance expression for fast primary electrons is: $\frac{\mathrm{j}_{\mathrm{ep}} \mathrm{A}_{\mathrm{f}}}{\mathrm{eV} \mathrm{V}_{\mathrm{ol}}}=\left[\mathrm{N}_{\mathrm{n}} \mathrm{S}_{\mathrm{in}}+\frac{1}{\tau_{\text {ep }}}\right] \mathrm{N}_{\mathrm{ep}}$ and for the positive ions: $\frac{\mathrm{j}_{\mathrm{i}} \mathrm{A}_{\mathrm{i}}}{\mathrm{eV} \mathrm{V}_{\mathrm{ol}}}=\mathrm{N}_{n} \mathrm{~S}_{\mathrm{i}} \mathrm{N}_{\mathrm{ep}}$. The primary electrons are emitted from the filaments of area $A_{f}, S_{i}$ is the ionization rate and $S_{i n}$, the inelastic collision rate. $A_{j}$ is the total ion loss area (including filaments), $\tau_{\text {ep }}$ is the fast electron confinement time and $V_{o 1}$ is the discharge volume. Eliminating $N_{e p}$ and using the Bohm stability criterion, we obtain: $\sqrt{\frac{m_{i}}{m_{e}}} \geq \frac{S_{i n}}{S_{i}} \frac{A_{i}}{A_{f}}+\frac{A_{i}}{\tau_{e p} N_{n} S_{i} A_{f}}$. This inequality can only be satisfied if the ratio $A_{i} / A_{f}$ is sufficiently small or if the discharge is at a sufficiently high gas pressure and high heating current. This agrees qualitatively with the curves, presented in Figure 2 where the oscillations disappear at high values of $P_{\text {ar }}$ and $I_{f}$.

\section{Acknowledgments}

The authors wish to acknowledge Dr. A. Verga, Dr. J.M. Layet for stimulating discussions..

\section{References}

[1] Quin J., Wang L., Yuan D.P., Gao P. and Zhang Z, Phys. Rev.Lett. 63 (1989) 163-166.

[2] Greiner F., Klinger T., Klostermann H.and Piel A., Phys. Rev. Lett. 70 (1993) 3071-3074.

[3] Fan S.H., Yang S.Z., Dai J.H., Zheng S.B., Yuan D.P.and Tsai S.T., Phys. Lett. A 164 (1992) 295-298.

[4] Bosch R.A. and Merlino R.L., Contrib. Plasma Phys. 26 (1986) 1-6.

[5] Klosterman H., Greiner F., Klinger T. and Piel A., Plasma Sources Sci. Technol. 3 (1994) 134-141. 